\title{
Alternative Load Path Analysis for Determining the Geometric Agreement of a Cable-Stayed Bridge with Steel Truss Girders
}

\author{
Xiaobo Zheng $\mathbb{D},{ }^{1}$ Gang Zhang $\left(\mathbb{D},{ }^{1}\right.$ Yongfei Zhang, ${ }^{1}$ and Leping Ren ${ }^{2}$ \\ ${ }^{1}$ School of Highway, Chang'an University, Xi'an, Shaanxi Province 710064, China \\ ${ }^{2}$ China Construction Third Engineering Bureau Group Co., Ltd., Xi'an, Shaanxi Province 710065, China \\ Correspondence should be addressed to Gang Zhang; zhangg_2004@126.com
}

Received 31 August 2021; Revised 27 October 2021; Accepted 28 October 2021; Published 16 November 2021

Academic Editor: Paolo S. Valvo

Copyright ( 92021 Xiaobo Zheng et al. This is an open access article distributed under the Creative Commons Attribution License, which permits unrestricted use, distribution, and reproduction in any medium, provided the original work is properly cited.

The geometric agreement, commonly hailed as load-transferring paths within bridge structures, is significantly crucial to the bridge structural mechanical performance, such as capacity, deformation, and collapse behavior. This paper presents a methodology dependent on alternative load paths to investigate the collapse behavior of a double-pylon cable-stayed bridge with steel truss girders subjected to excess vehicle loading. The cable-stayed bridge with steel truss girders is simplified using a series-parallel load-bearing system. This research manifests that the enforced vehicle loading can be transferred to alternative paths of cablestayed bridges in different load-structure scenarios. A 3-D finite element model is established utilizing computer software ANSYS to explore the collapse path of cable-stayed bridge with steel truss girders, taking into account chord failure, loss of cables together with corrosion in steel truss girders. The results show that chord failures in the mid-portion of the mainspan result in brittle damage in truss girders or even sudden bridge collapse. Further,the loss of long cables leads to ductile damage with significant displacement.The corrosion in steel truss girders has a highly slight influence on the collapse behavior of cable-stayed bridge. The proposed methodology can be reliably used to assess and determine the vulnerability of cable-stayed bridge with steel truss girders during their service lifetime, thus preventing structural collapses in this type of bridge.

\section{Introduction}

Bridge structural collapse is characterized with collapse of an entire structure or a disproportionate portion in structure resulting from initial local failure in an individual member. The failures of critical members in bridge structures typically occur due to overloading. Cable-stayed bridges with steel truss girders are widely applied for bridge construction spanning rivers and valleys. The truss girders can provide sufficient and harmonious space for vehicles and trains individually due to double-layer driving, and also the cables can supply adequate tension on truss girders to maximize the bridge span, as shown in Figure 1. Unfortunately, some of these bridges have collapsed commonly originated from damage produced by heavy live loads. For example, the chords and joints can be damaged by fatigue, such as the I-35W Highway Bridge over the Mississippi River in Minneapolis, which collapsed suddenly, resulting in the death of
13 and injury to 145 people, as shown in Figure 2 [1]. Similarly, the sudden failure of a single rod led to the fracture of several other rods, causing the collapse of the Silver Bridge over the Ohio River between Ohio and West Virginia, resulting in the death of 46 people [2].

Bridge systems are vulnerable to collapse under extremely heavy loads due to the complicated connections of components and low robustness. Existing assessment approaches fall into three categories: the deterministic method, the probability and reliability method, and the risk-based approach [3].

The deterministic method assesses structural safety in terms of displacement under loads, structural capacity, and energy and component sensitivity. Pandey and Barai proposed the structural response sensitivity to measure redundancy for continuum and discrete structures and assess structural damage [4]. Nafday proposed the minimum difference between the stiffness matrix and singular matrices and the correlation between the stiffness matrix and column vector as 


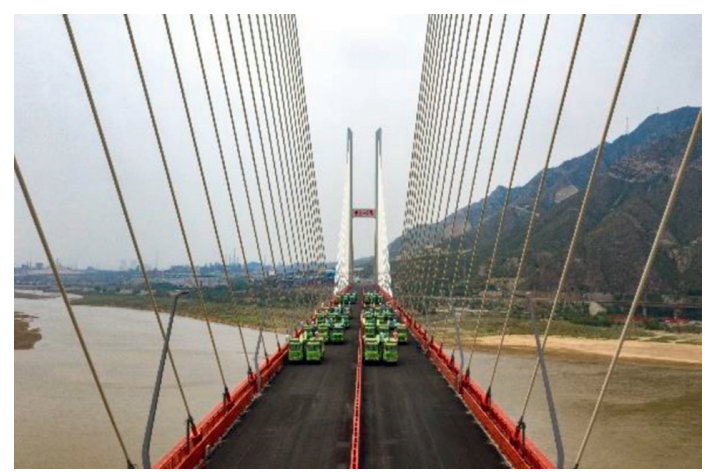

Figure 1: Yu Men Kou Huanghe River Bridge.

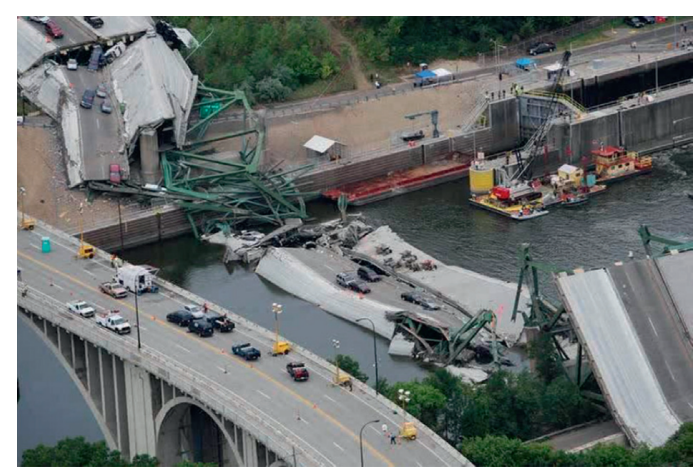

FIgUre 2: Collapse of the I-35W Highway Bridge [1].

safety indices for discrete structures [5]. In addition, methods for determining the key structural components and the failure path were also proposed [5]. Hunley and Harik investigated the redundancy of double-steel box curved beam bridges, considering the effects of the span, continuity, curvature, damage location of the beam, external supports, and girder spacing on bridge failure [6]. The study indicated that additional criteria to those in the American Association of State Highway and Transportation Officials (AASHTO) Load and Resistance Factor Design (LRFD) code were required to ensure the redundancy of the double-steel box curved beam bridge system [6]. NCHRP 406 is a study of the collapse resistance of various structural systems [7]. A system factor table was developed for common-type bridges, including simple and continuous bridges with multiple girders, and step-by-step calculations are provided to assess the redundancy of bridges with complex structures [7]. The collapse behavior of long-span bridges was analyzed using experiments and numerical simulations [8-12]. In the literature [8], the collapse behavior of a suspension bridge and cable-stayed bridge due to sudden cable loss was investigated. A dynamic amplification factor (DAF) of 2.0 was required to meet the safety requirements of the cable design; the cable-stayed bridge did not survive the sudden loss of more than two cables [8]. The bending moments enforced on the cross sections of bridge girders were computed to determine the importance in ultimate limit state of failure at a stay location in cable-stayed bridge. The average DAF values of the undamped and damped movements were 3.35 and 2.52, respectively, for the positive bending moments [9]. The average DAF values of the axial stress in the pylon cross-sections and the stays of a cable-stayed bridge were smaller than 2.0 and 1.68 for the undamped movement and 1.47 for $2 \%$ of the critical damping, respectively [10]. A model describing large displacement effects and internal damage and time-dependent damage functions were established to describe the constitutive relationships [11]. The results showed that the sudden failure of cables resulted in DAF values of 2.5-3.5 for vertical displacement, 5.5-8.5 for the bending moment, and 1.3-2.8 for torsional rotation in the midspan [11]. The cable system of a hybrid cable-stayed/suspension (HCS) bridge can redistribute the additional stresses produced by internal damage of the bridge components [12]. To reflect the structural safety of cablestayed bridges before and after damage quantitatively, a technique based on the plastic limit analysis is proposed, considering the change of ultimate load-carrying capacity [13]. To classify the twin steel tub girder bridges as redundant and nonfracture critical, the effect of key parameters on redundancy are investigated, thus relieving concerns over selection of this bridge type by reducing fabrication and life-cycle inspection costs [14]. Extreme load and hazards as well as the cost in maintenance were taken into account based on literature, with the focus on the effects of collapse of bridges [15].

Four reliability indices were developed for the four limit states of a bridge under heavy static loads, namely, member failure, ultimate limit state, functionality limit state, and damage limit state [3]. The differences in the reliability indices of the member failure in the latter three limit states are the structural redundancies, as demonstrated with a standard TS20 truck load [3]. Consequently, several approaches based on reliability have been developed to assess structural redundancy and failure probability due to insufficient capacity and overload [16-20]. In [16, 17], the geometric configuration and safety of a truss bridge system were analyzed using system reliability, considering the uncertainties of the critical members and future loads. It was shown that the system safety, which influences public security and national defense, depended on the number of girders, the girder spacing, and the presence of diaphragms [17]. The target reliability index was calculated by considering the expected life of the structure, importance of individual members, design experience, and material costs [18]. This index was used to determine the members' strength and applicability and prevent fatigue damage [18]. The redundancy concept has been applied to many types of infrastructures. The target reliability index provides a good balance between safety and costs in infrastructure networks $[19,20]$. It is noticeable that the consequences of structural collapse can take several forms in the range of structural damage and human injuries to functional downtime and environmental impact, including the probability of structural damage and the causing economic and social effect [21-26]. It is shown that structural collapse should be categorized by the economic, social, and environmental consequences as well as human loss [21].

Many significant results have been obtained from studies focusing on redundancy and collapse of structures. However, it is necessary to extend the current methodologies to long-span bridges. The simplified deterministic approach for assessing the collapse behavior of suspension bridges has been extended to complex bridge systems, such as arch bridges and cable-stayed bridges. In this study, the deformation and cable force of a 


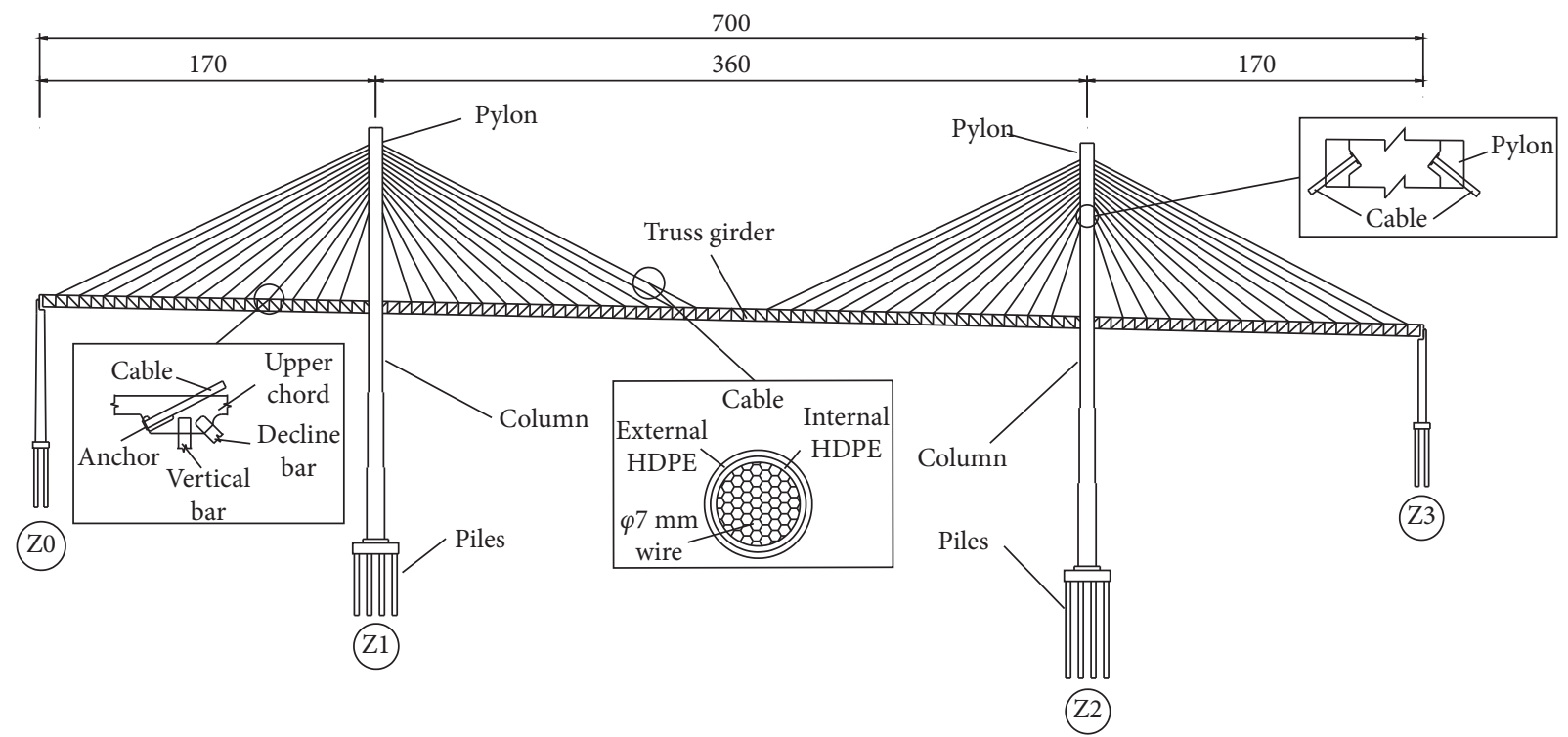

FIgURE 3: Double-pylon cable-stayed bridge with steel truss girders (Units: m).

double-pylon cable-stayed bridge with steel truss girders are considered using a series-parallel load-bearing system to investigate the transfer of the absorbed loads to alternative paths in different scenarios. The collapse behavior of the bridge is analyzed using increasing traffic loads to determine the optimal structural system. It is shown that the series-parallel loadbearing system of the structural members affects the mechanical behavior of the cable-stayed bridge system.

\section{Selection and Description of Cable- Stayed Bridge}

The cable-stayed bridge has a total length of $700 \mathrm{~m}$, with $360 \mathrm{~m}$ between the two pylons and $170 \mathrm{~m}$ on each side of the pylons, as shown in Figure 3. The main beam consists of 2 truss girders with a height of $6 \mathrm{~m}$ and spacing of $26 \mathrm{~m}$. The chords have box sections, and the vertical and diagonal bars have $\mathrm{H}$-shaped sections; 104 steel-wire cables are anchored in the truss girder and the pylons. Each pylon consists of 3 parts, with lengths of $133.5 \mathrm{~m}, 38 \mathrm{~m}$, and $38 \mathrm{~m}$ or $44 \mathrm{~m}$. The material properties are listed in Table 1.

\section{Numerical Model}

The alternative load paths of the bridge during the failure of individual members are investigated to study the collapse behavior of the cable-stayed bridge. A numerical model is established to simulate the performance of the bridge under vehicle loads in different cases and is verified by an experiment using live loads.

3.1. Analysis Details. Without alternative load paths, a bridge can collapse entirely or partially under a load. If a cable-stayed bridge consisting of a steel truss girder and cables collapses entirely when the girder fails, the girder lacks alternative load paths, as depicted in Figure 4(a). In contrast, the bridge does not collapse when one cable fails if the adjacent cables act as alternative load paths and bear the absorbed load from the failed cable, as shown in Figure 4(b). For the analysis of the structural load paths, the cable-stayed bridge can be simplified as a conceptual model that includes series and parallel systems, as shown in Figure 5. The girder segments, which lack alternative load paths, comprise the series system, whereas the cables with many alternative load paths form the parallel system.

The conceptual collapse model of the series-parallel system depicts the configuration of the alternative load paths in the cable-stayed bridge. These load paths significantly affect the collapse behavior. The loss of chords in the truss girder and the failure of cables correspond to the series and parallel systems, respectively. The truss girder segments of the two trusses are illustrated in Figure 5. Each truss section with upper and lower chords and bars provides limited alternative load paths, indicating that the failures of the upper and lower chords would significantly decrease the capacity of a truss section. If the chords fail, the limit alternative load paths in the truss girder represent the series system. Thus, if a small deformation occurs before the collapse, the cable-stayed bridge is prone to global collapse, indicating an insufficient number of alternative load paths to absorb the loads from the lost chords. In contrast, the cables represent a parallel system, providing a sufficient number of alternative load paths, which is reflected by changes in the forces in the adjacent cables in the damage model of the cable loss scenario. A change in the cable forces and the large deformation before total collapse indicate that the loading of the failed cables is absorbed by the other cables.

The series and parallel system model is used to assess the collapse behavior of the bridge. A three-dimensional finite element model (3D FEM) is established to simulate the bridge under different load scenarios and is verified using a live load experiment. The mechanical behavior of the bridge (force and 
TABLE 1: Material properties of the cable-stayed bridge.

\begin{tabular}{lccc}
\hline Members & Material & Modulus of elasticity $(\mathrm{MPa})$ & Sectional area $\left(\mathrm{m}^{2}\right)$ \\
\hline Pylon & Concrete $\left(f_{\mathrm{cu}} \cdot k=32 \mathrm{MPa}\right)$ & $3.45 \times 104$ & $16.04 \sim 27.0$ \\
Deck & Concrete $\left(f_{\mathrm{cu}} \cdot k=26 \mathrm{MPa}\right)$ & $3.25 \times 104$ & 4.70 \\
Truss girder & Steel $\left(\sigma_{S}=370 \mathrm{MPa}\right)$ & $2.06 \times 105$ & 0.10 \\
Horizontal and lateral bars & Steel $\left(\sigma_{S}=345 \mathrm{MPa}\right)$ & $2.06 \times 105$ & $0.27 \times 10^{-1}$ \\
Cables (per) & $\varphi 7 \mathrm{~mm}$ wire $\left(f_{p k}=1670 \mathrm{MPa}\right)$ & $1.95 \times 10^{5}$ & $(0.53 \sim 1.34) \times 10^{-2}$ \\
\hline
\end{tabular}

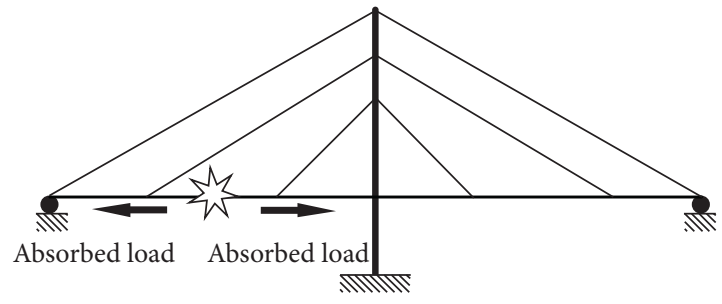

(a)

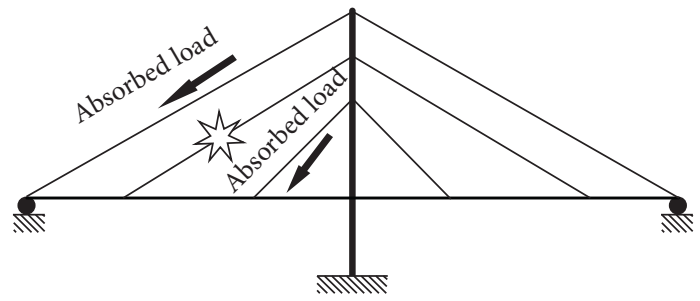

(b)

FIgURE 4: Failures of individual members of the cable-stayed bridge: (a) load transfer after girder failure; (b) load transfer after cable failure.

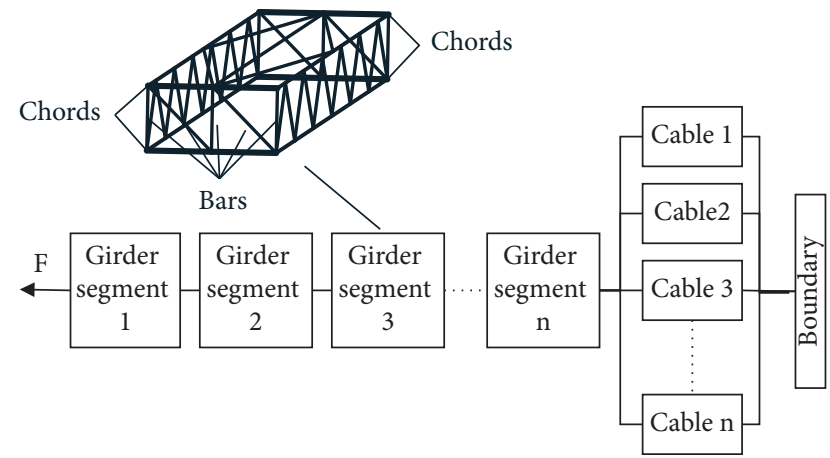

FIGURE 5: Series and parallel system of the cable-stayed bridge.

deformation) after the removal of individual members and the corrosion of the truss girder is investigated. In addition, the damaged bridge after the removal of chords and cables is thoroughly analyzed to investigate its capacity and collapse behavior. The mechanical behavior is assessed with the seriesparallel structural system to determine alternative load paths. The flowchart of the analysis is shown in Figure 6.

3.2. Numerical Discretization. The 3D FEM is established in the ANSYS software to study the structural collapse behavior. The pylons and truss girder are discretized using BEAM189 elements, and the cables are modeled with LINK180 elements. MPC184 rigid link/beam elements are used to connect the cables and pylons. BEAM189 has three nodes with six degrees of freedom at each node, i.e., three translations in the nodal $x$-, $y$-, and $z$-directions and three rotations around the $x$-, $y$-, and $z$-axes [27]. The beam element is based on the Timoshenko beam theory, which includes shear deformation effects; thus, it is suitable for analyzing 3D slender to moderately stubby/thick beam structures. LINK 180 has two nodes with three degrees of freedom per node, i.e., translations in the nodal $x$-, $y$-, and $z$-directions [28]. This element does not bend or rotate, making it suitable for modeling 3D cables, links, and springs. The MPC184 rigid link/beam has two nodes with six degrees of freedom at each node, i.e., three translations in the nodal $x$-, $y$-, and $z$-directions and three rotations around the $x$-, $y$-, and $z$-axes.

This element models a rigid constraint or a rigid component. The material stiffness properties are not required; thus, it can be used to simulate a rigid constraint between two deformable bodies or a rigid component that transmits forces and moments. To simplify the supports on the pylons, the translations of the nodes of the tie beam of the pylons and the nearby nodes of the truss girder are coupled in the nodal $x$-and $z$-directions. The ends of the pylons are constrained in all degrees of freedom, i.e., three translations in the nodal $x-, y$-, and $z$-directions and three rotations around the $x-, y$-, and $z$-axes [29]. The supports at the ends of the truss girder are simulated by constraining some degrees of freedom, i.e., translations in the nodal $z$-direction and $x$ direction with an allowance of $\pm 500 \mathrm{~mm}$.

The node-to-node interactions are modeled to finely discretize the structural model and illustrate the common action of the cable-stayed bridge [30]. Common nodes are shared between the beam elements of the truss girder and the link elements of the cables, between the link elements of the cables and the rigid link/beam elements of the rigid connections, and between the beam elements of the pylons and the rigid link/beam elements of the rigid connections [31]. The 3-D structural model, the mesh, and the constraints for the structural analysis are shown in Figure 7.

Inelastic material properties are adopted in the FEM for the structural collapse analysis under extremely heavy vehicle loading. The cables and truss girder have ideal elastic-plastic properties with yield strengths of $1670 \mathrm{MPa}$ and $370 \mathrm{MPa}$, respectively (Table 2). All the failures of the chords and bars of the steel truss girder subjected to considerable compression are considered in the analysis since they may lead to bridge collapse. As the static load increases, the data on the member failure and the changes 


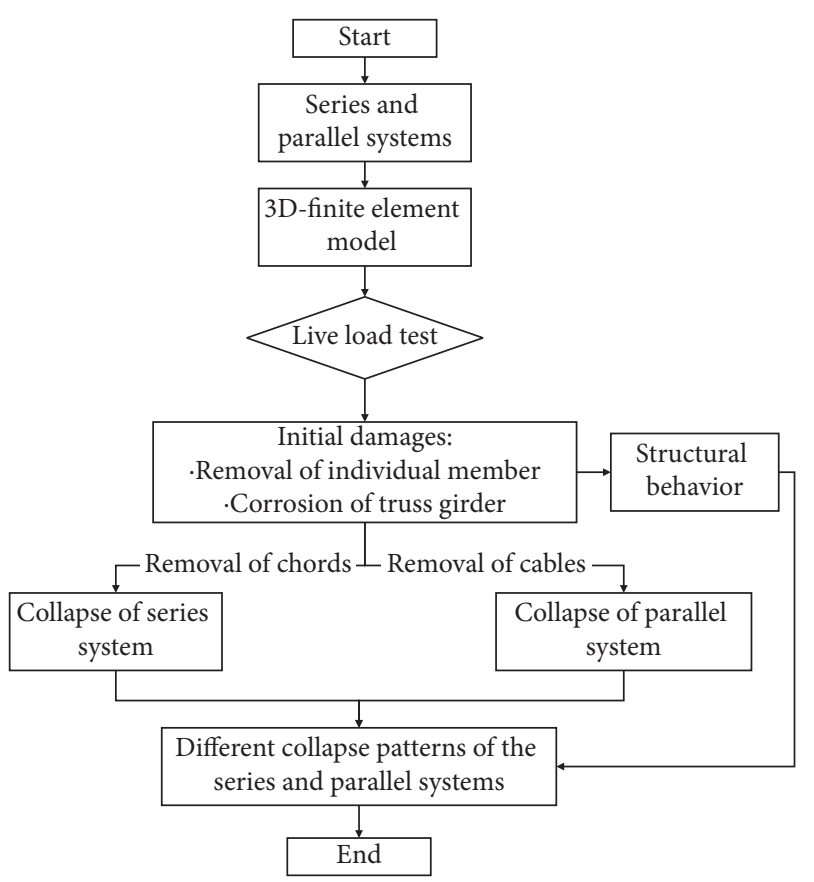

Figure 6: Flowchart of the collapse analysis of the cable-stayed bridge.

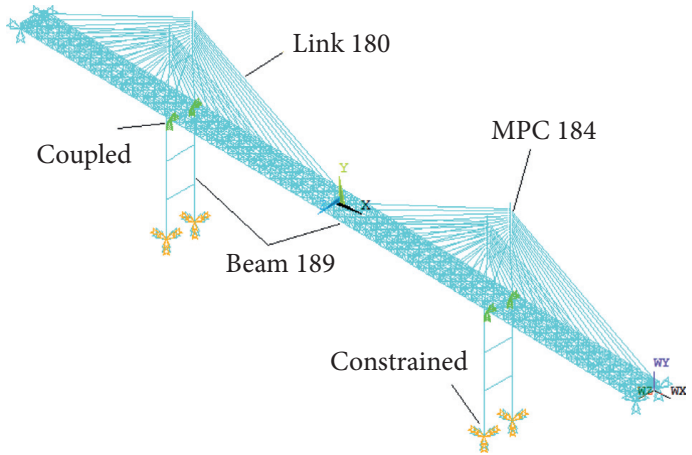

FIgURE 7: Finite element model of the cable-stayed bridge.

TABLE 2: Strain of the chords for the three load cases.

\begin{tabular}{|c|c|c|c|c|c|}
\hline \multirow{2}{*}{ Load case } & \multirow{2}{*}{ Section } & \multirow{2}{*}{ Strain gauge location } & \multicolumn{2}{|c|}{ Strain $(\mu \varepsilon)$} & \multirow{2}{*}{ Ratio } \\
\hline & & & Measured & FE model result & \\
\hline \multirow[b]{2}{*}{1} & \multirow{2}{*}{ I-I } & Upper chord & -134 & -150 & 0.89 \\
\hline & & Lower chord & 159 & 165 & 0.96 \\
\hline \multirow{2}{*}{2} & \multirow{2}{*}{ II-II } & Upper chord & -87 & -90 & 0.97 \\
\hline & & Lower chord & 75 & 79 & 0.95 \\
\hline \multirow{2}{*}{3} & \multirow{2}{*}{ III-III } & Upper chord & -228 & -231 & 0.99 \\
\hline & & Lower chord & 190 & 204 & 0.93 \\
\hline
\end{tabular}

in the forces are recorded until the analysis is terminated when the bridge collapses.

3.3. Calibration of Numerical Model. The selected bridge is subjected to a live load test to calibrate the 3D FEM of the cable-stayed bridge (Figure 8). Thirty-two strain gauges are attached to the upper and lower chords to determine the mechanical performance of the truss girder, and the bridge is subjected to a standard truck load (Figure 9). The strain gauges are connected to a wired data acquisition system to collect the data.

According to the influence line of the cable-stayed bridge, three load cases are designed to obtain the critical bending moments in the side and main spans. Three-axle dump trucks with a combined axial weight of $300 \mathrm{kN}$ are 


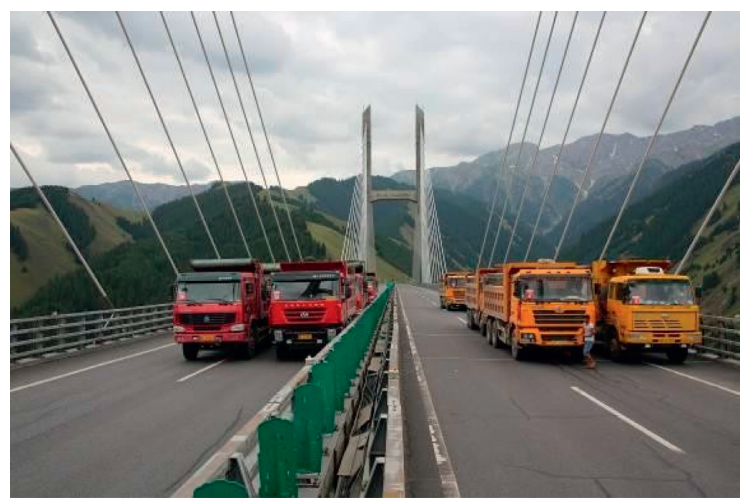

Figure 8: Live load test.

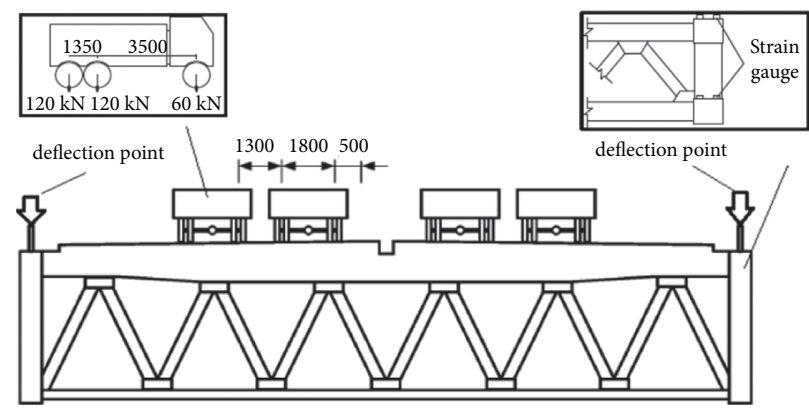

Figure 9: Cross-sectional view and load paths (units: mm).

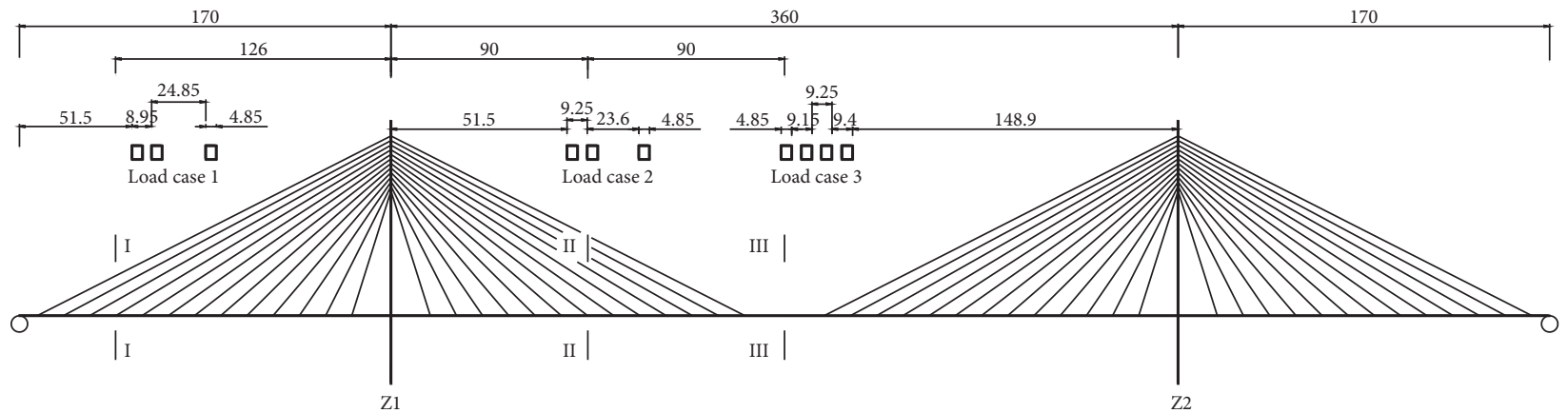

Figure 10: Longitudinal view and load paths (units: m).

TABLE 3: Vertical displacement of sections for the three load cases.

\begin{tabular}{lcccc}
\hline \multirow{2}{*}{ Load case } & \multirow{2}{*}{ Section } & \multicolumn{2}{c}{ Vertical displacement $(\mathrm{mm})$} & \multirow{2}{*}{ Ratio } \\
& & Measured & FE model result & \\
\hline 1 & I-I & 87 & 92 & 0.95 \\
2 & II-II & 101 & 104 & 0.97 \\
3 & III-III & 214 & 221 & 0.97 \\
\hline
\end{tabular}

used to apply the loading. The axle weights of the trucks are $60 \mathrm{kN}$ for the front axle and $120 \mathrm{kN}$ for each of the two rear axles, and the axial spacing is $3.5 \mathrm{~m}$ at the front and $1.35 \mathrm{~m}$ at the back, as shown in Figure 9. Figures 9 and 10 show the location of applying the truck load in a cross-sectional and longitudinal view and the locations of the deflection points. The data are used to obtain the vertical deformation of the truss girder.
Table 2 shows the three load cases, the strain gauge locations, the measured strain, and the strain obtained from the FEM. Similarly, the vertical displacement values obtained from the measurements and the FEM for the three load cases are listed in Table 3.

The ratios of the measured strain and vertical displacement to the FEM model results in Tables 2 and 3 range from 0.89 to 0.99 for the three load cases, indicating a good agreement between the measured and modeled results. Therefore, the FEM accurately simulates the behavior of the cable-stayed bridge with steel truss girders subjected to heavy truck loading.

3.4. Analysis Procedure. The instability of the truss girder and the failure of the cables can result in the collapse of the cable-stayed bridge subjected to high vertical loading. Steel 


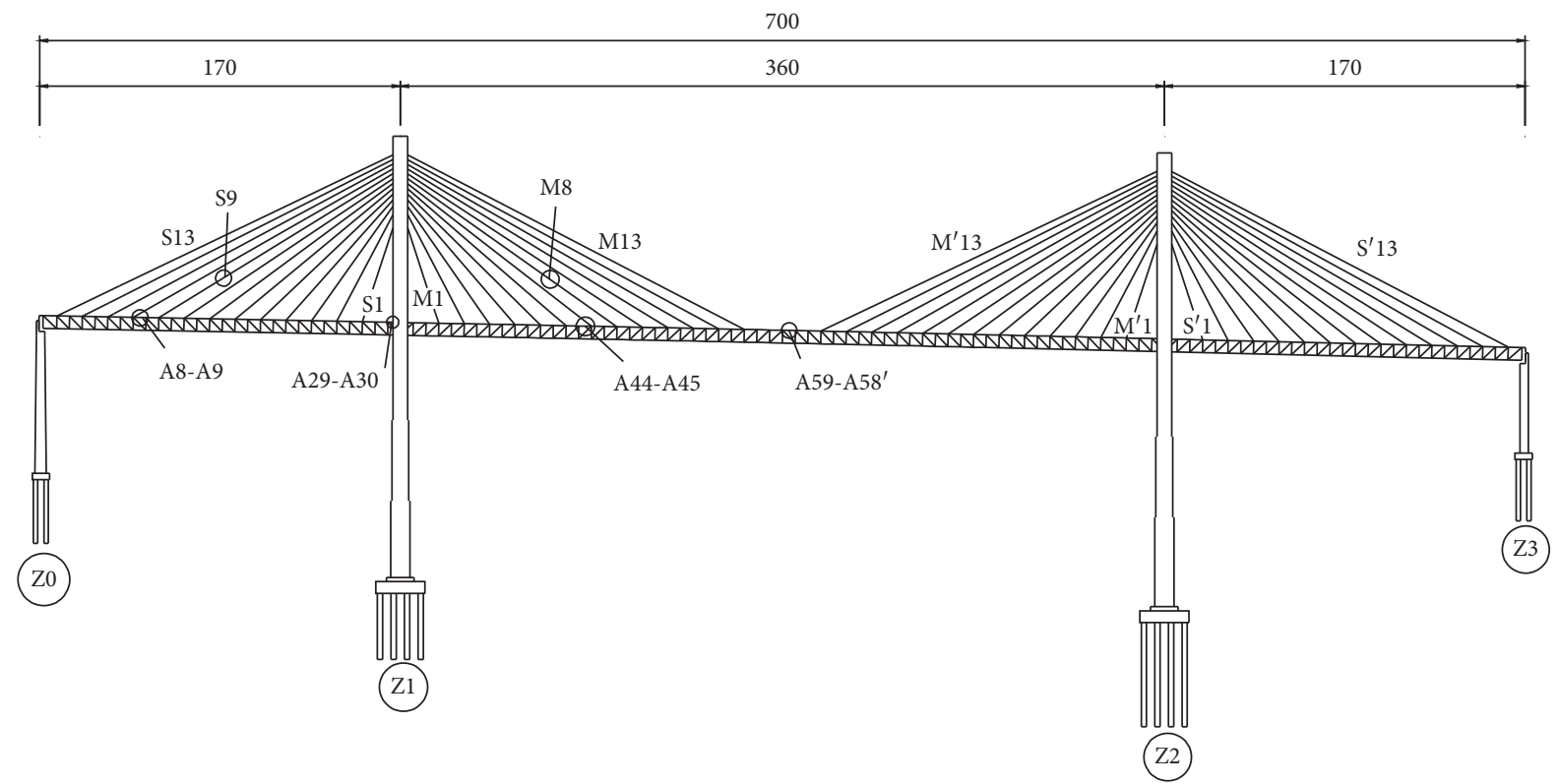

FIgURE 11: Failed members and corroded bridge sections (units: m).

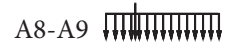

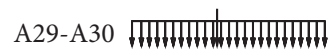

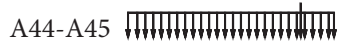

A59-A58'

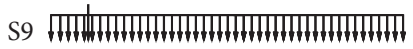

M8

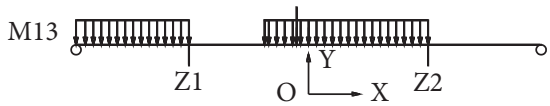

FIGURE 12: Loading location for the loading scenarios.

TABLE 4: Load types and placement for different loading scenarios.

\begin{tabular}{lcc}
\hline Failed members & & Loading location \\
\hline A8-A9 & Uniform load & Concentrated load \\
A29-A30 & Entire side span & $-306 \mathrm{~m}$ \\
A44-A45 & $-350 \mathrm{~m}$ to $-60 \mathrm{~m}$ & $-218 \mathrm{~m}$ \\
A59-A58' & $-350 \mathrm{~m}$ to $-40 \mathrm{~m}$ & $-90 \mathrm{~m}$ \\
S9 & $-60 \mathrm{~m}$ to $60 \mathrm{~m}$ & $0 \mathrm{~m}$ \\
M8 & Side span and main span & $-294 \mathrm{~m}$ \\
M13 & Side span and main span & $-78 \mathrm{~m}$ \\
\hline
\end{tabular}

corrosion can significantly change the material properties, such as the elastic modulus and yield strength, potentially causing failure of the members or bridge collapse. We analyzed the ultimate capacity of the bridge by removing individual members. Without alternative load paths, the cablestayed bridge collapses, resulting in the automatic termination of the analysis in the software. The effect of corrosion of the truss girder on the mechanical behavior of the bridge is assessed by changing the cable forces and the deformation level of the truss girder. The removed members and the corroded sections of the cable-stayed bridge are depicted in Figure 11.

According to the influence line of the members of the bridge, it is assumed that chords A8-A9, A29-A30, A44A45, and A59-A58' and cables S9, M8, and M13 failed. According to the Technical Standards for Highway 


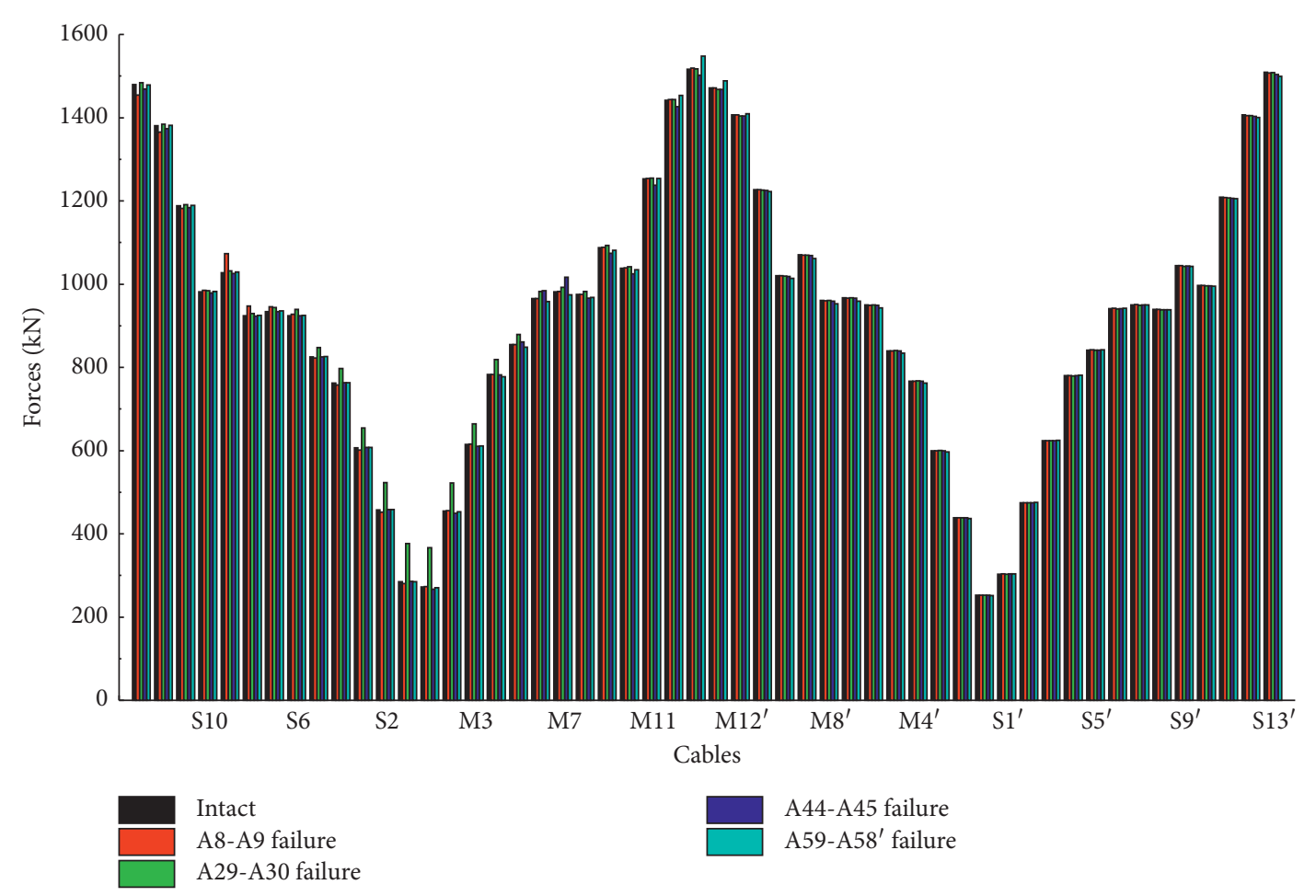

Figure 13: The cable forces in the chord loss scenarios.

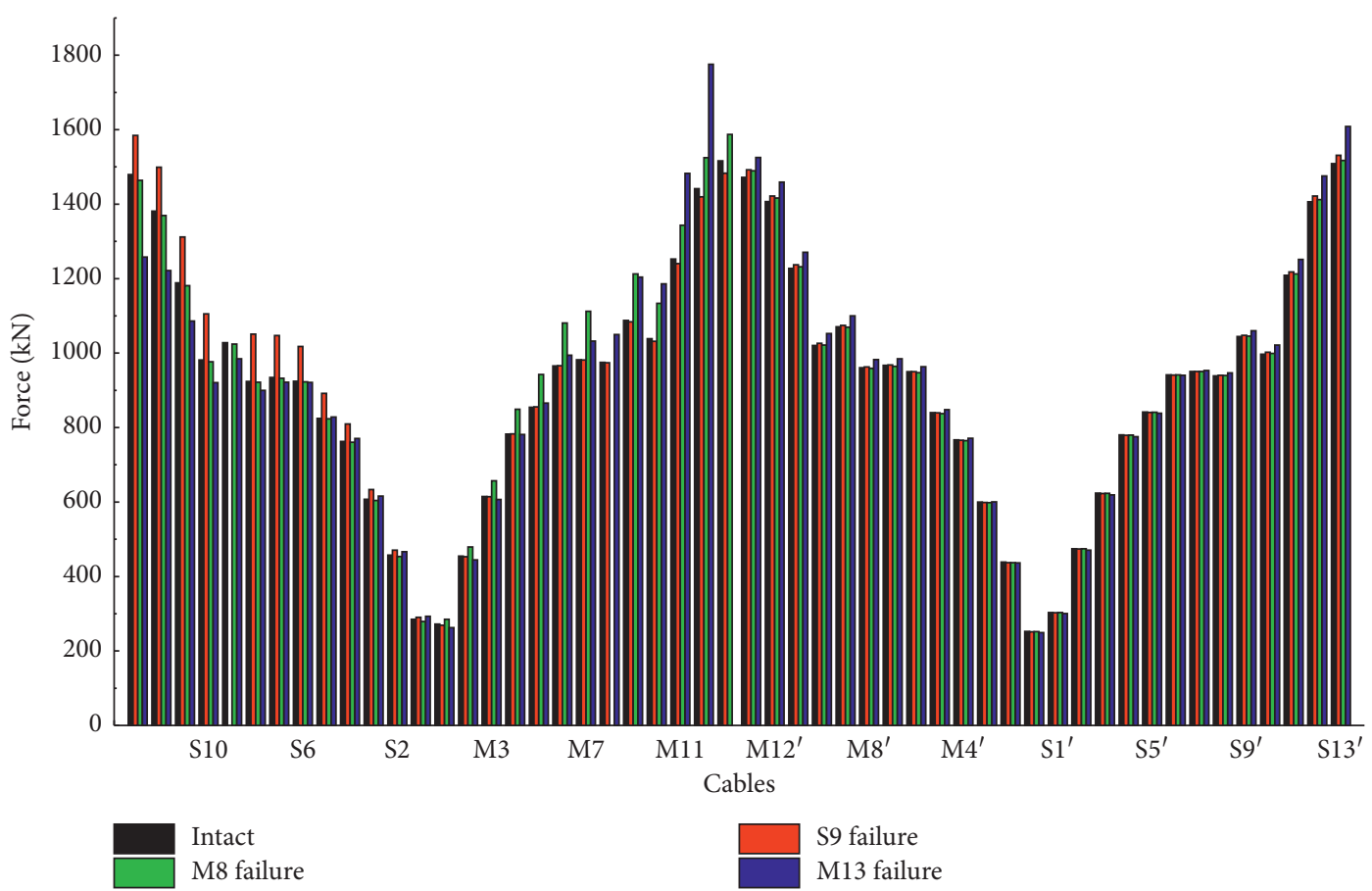

FIgURE 14: The cable forces in the cable loss scenario.

Engineering (JTG B01-2014), the Highway-I lane loading is combined with a concentrated force of $360 \mathrm{kN}$ and a uniformly distributed load of $10.5 \mathrm{kN} / \mathrm{m}$. The loading types and placements causing bridge collapse are shown in Figure 12 and Table 4.

\section{Results and Discussion}

Two load scenarios, the removal of individual chords and cables, and corrosion of the truss girder sections are considered to conduct an in-depth analysis of the response of the collapsing 


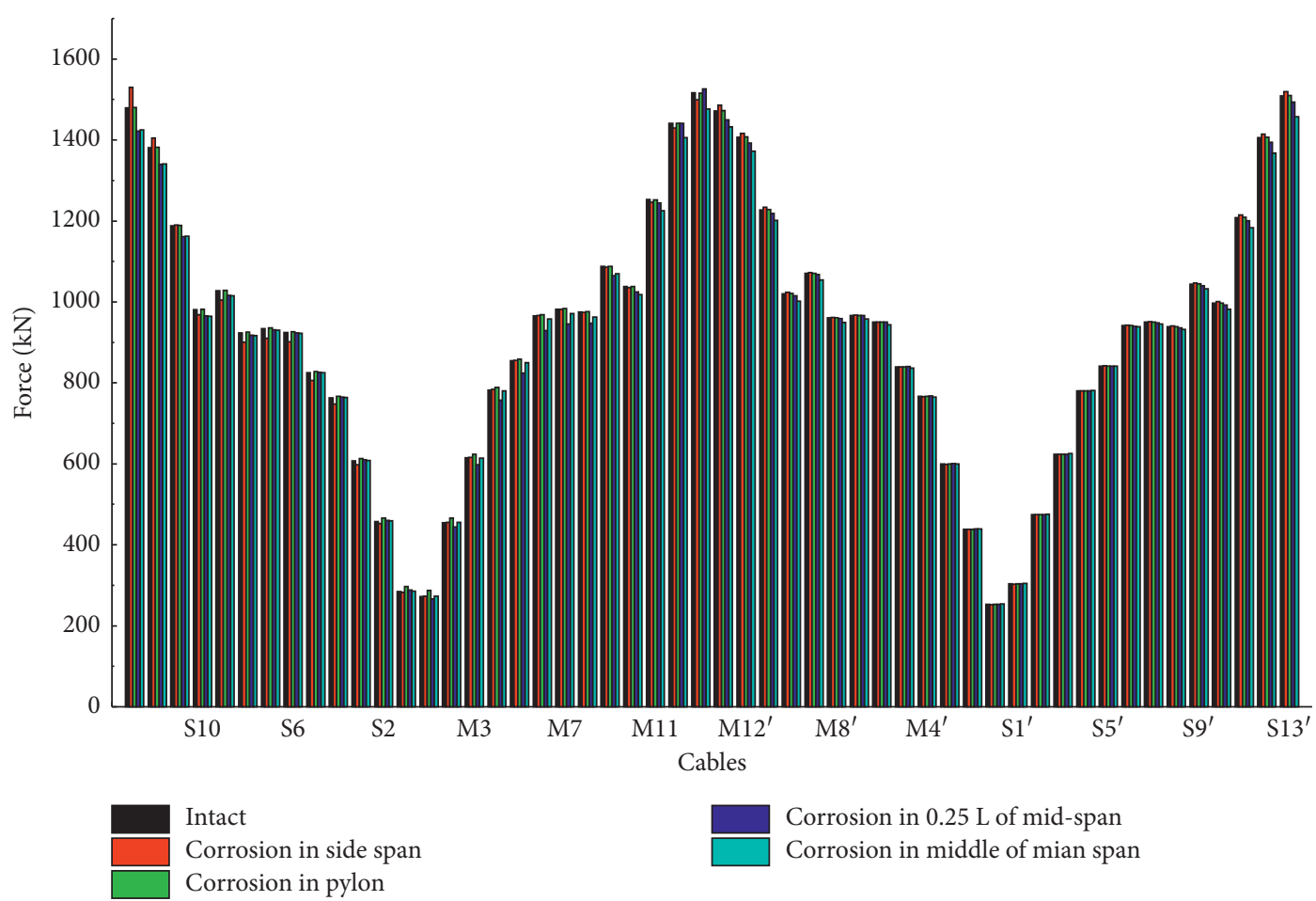

FIGURE 15: The cable forces in the corroded truss girder scenario.

cable-stayed bridge. The relationship between the load and displacement and the collapse patterns are investigated.

4.1. Damage to the Cable-Stayed Bridge. The failures of the chords A8-A9, A29-A30, A44-A45, and A59-A58' and the cables S9, M7, and M13 change the internal forces of the truss girder and cables, as depicted in Figures 13 and 14. Compared to the intact bridge, the forces of cables S6, S7, S8, S9, and S10 increase by $0.3 \%$ to $4.4 \%$, while the forces of cables S1 to S5 and S11 to S13 decrease by $0.3 \%-1.7 \%$. The loss of chords A29-A30 reduces the force of cables M1 and $\mathrm{S} 1$ anchored in the girder of the side span by a maximum of $34.7 \%$ and $32.1 \%$, respectively, and the proportion increases toward the pylon. In contrast, the failures of chords A29-A30 or A59-A58' do not significantly increase the cable forces (a maximum increase of 3.5\%). Since the truss girder is a series bearing system with a lack of alternative load paths, the absorbed load is not transferred to the cables, resulting in small changes in the cable forces.

In the cable S9 loss scenario, the increase in the axial force of the cables in the side span ranges from $1.9 \%$ to $13.8 \%$, and the force of the other cables changes only slightly. The failure of cable M8 results in an increase in the cable force ranging from $4.7 \%$ to $13.3 \%$. The decrease in the axial force of cables S6 to S13, M1 to M4, and M2' to S6' is a minimum of $15 \%$ in the cable S13 loss scenario, while the increase in the axial forces of cables S5 to S1, M5 to M3', and $\mathrm{S}^{\prime}$ to $\mathrm{S} 13^{\prime}$ ranges from $0.1 \%$ to $23.2 \%$. Since the cables are a parallel bearing system with many alternative load paths, the absorbed load is transferred to the other cables, reflected in the changes in the cable forces.
The material properties can be changed by the corrosion of members, resulting in different properties for different corrosion rates. It is assumed that the corrosion rate equals $10 \%$ of the bars and chords in sections I, II, III, and IV of the truss girder (Figure 11). The calculated values of the elastic modulus and tensile strength of the materials are $146.26 \mathrm{GPa}$ and 292.3 $\mathrm{MPa}$, respectively. These values lead to the changes in the forces of the cables subjected to a dead load, as depicted in Figure 15.

Compared to the cable forces of the intact bridge, the forces in cables S5, S6, S7, S9, and S10 decrease from $2.2 \%$ to $2.6 \%$, with a $3.4 \%$ increase in the force of cable 13 in section I corrosion scenario. Similarly, the force in cable M1 increases by $5.7 \%$ in section II corrosion scenario, while the corrosion in section III leads to a reduction in the forces of cables M1 to $\mathrm{M} 10$ and S9 to $\mathrm{S} 13$ of $2.0 \%$ to $3.7 \%$ and 1.1 to $3.9 \%$, respectively. The forces of cables S13, M13, and S13 decrease by $3.7 \%, 2.7 \%$, and $3.4 \%$, respectively, in section IV corrosion scenario. In contrast, the corrosion of the girder has a negligible effect on its vertical displacement, with a maximum value of $14 \mathrm{~mm}$ (Figure 16). The truss girder, a series bearing system, does not transfer the absorbed load to the cables if the main beam is corroded due to an insufficient number of alternative paths.

4.2. Collapse Behavior. The loss of chords A8-A9, A29-A30, A44-A45, and A59-A58 causes a decrease in the ultimate capacity and ductility of the remaining structures. Figure 17 depicts the axial and vertical displacements of the girder of the remaining structures subjected to increasing traffic loading. 


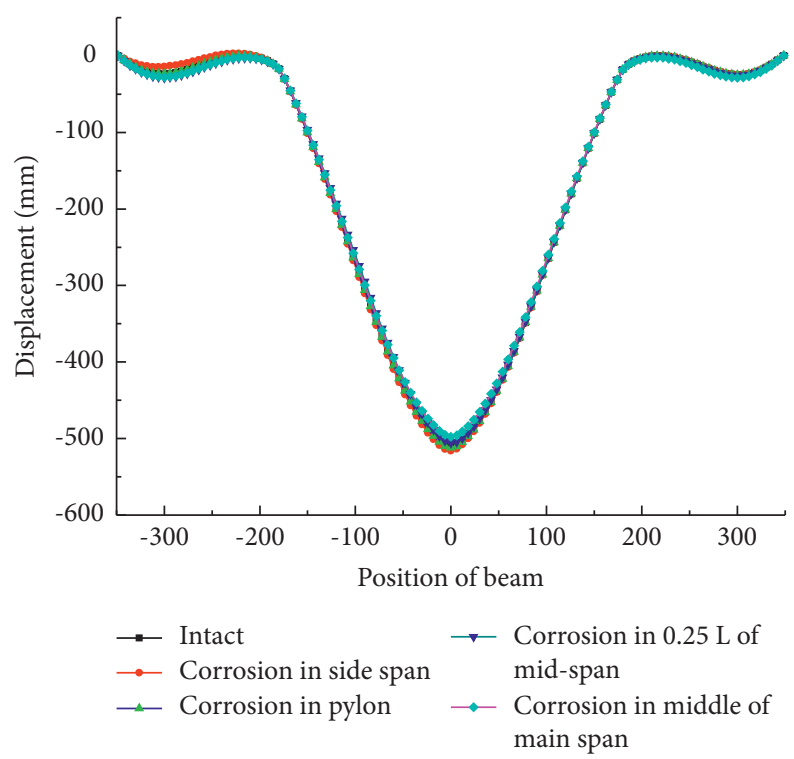

Figure 16: Vertical displacement in the corroded truss girder scenario.

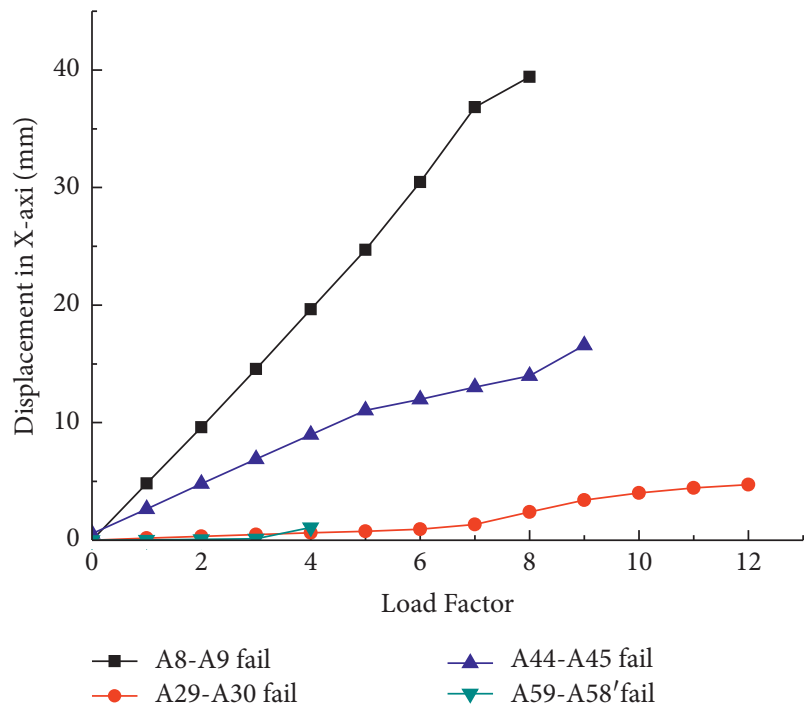

(a)

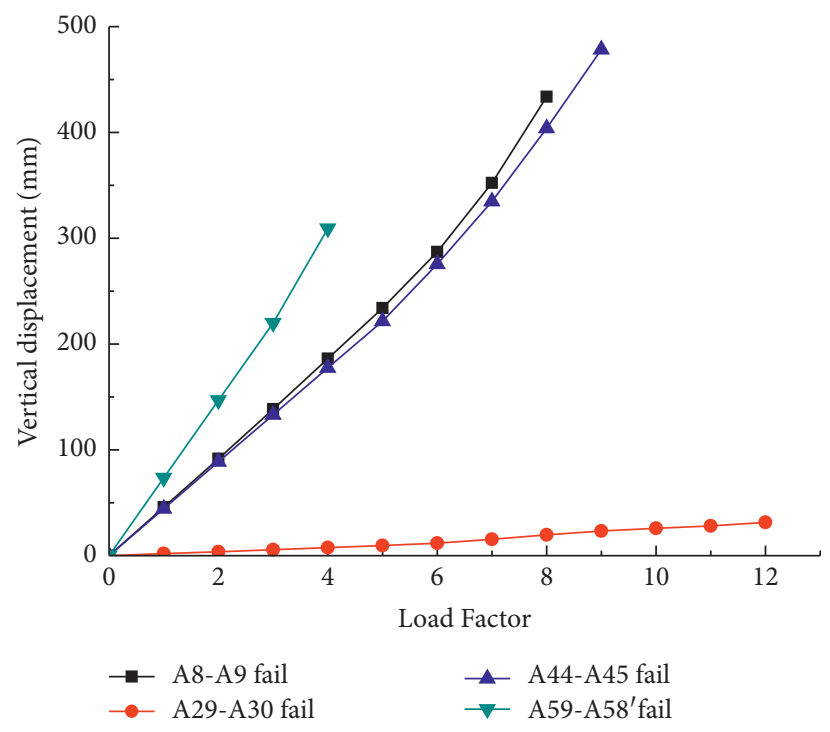

(b)

Figure 17: Displacement of the girder in the chord loss scenarios: (a) axial displacement-load response obtained from the finite element model; (b) vertical displacement-load response obtained from the finite element model.

In the chord loss scenarios A8-A9, A29-A30, A44-A45, and A59-A58, the vertical displacement values of the degraded structures are much larger than the lateral values when the bridge is subjected to high traffic loading. The remaining structures exhibit significant deflection and collapse when chords A8-A9, A44-A45, and A59-A58 are lost. In the chord loss scenario A59-A58, the axial displacement of the girder increases rapidly, whereas the vertical displacement is very small. The degraded bridge can bear 12 times the design load, but its deflection, including the vertical and axial displacement, is very small. The collapse patterns of the bridges for different loading cases are depicted in Figure 18, and the maximum displacements and load factors are listed in Table 3. The brittle collapse of the damaged bridge occurs without deformation. Since the truss girder is a series bearing system, the load is transferred in limited paths to the truss girder after the individual chords fail.

The loss of cables S9, M8, and M13 leads to a decrease in the ultimate capacity and ductility of the remaining structures. Figure 19 depicts the axial and vertical displacements of the girder of the remaining structure subjected to increasing traffic loading. Under the critical loading, the remaining structure exhibits significant vertical displacement before it collapses, indicating insufficient ductility of the degraded bridge. The axial and vertical displacement 


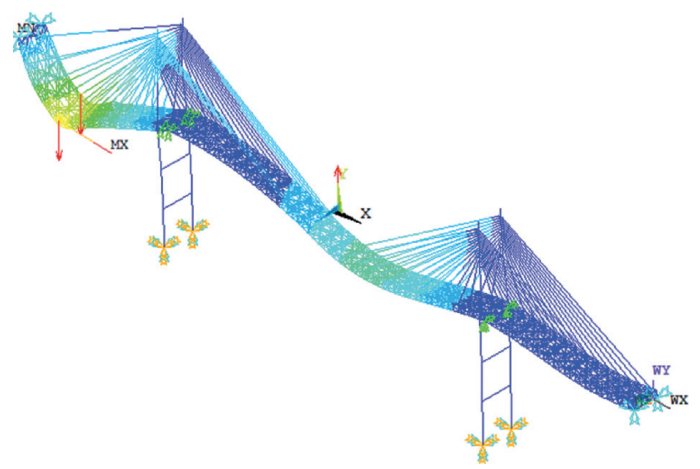

(a)

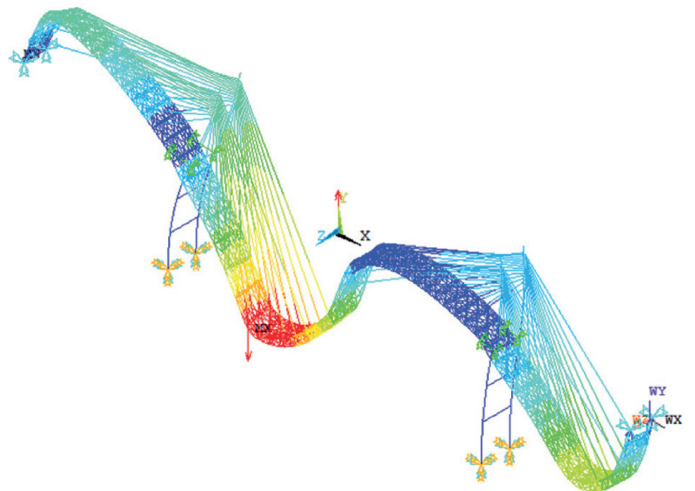

(c)

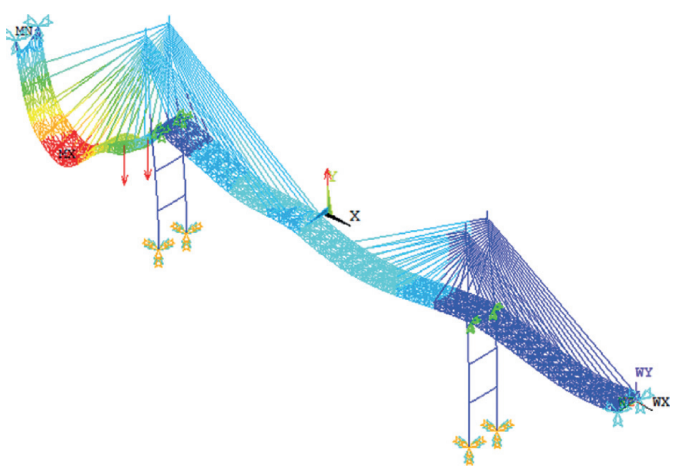

(b)

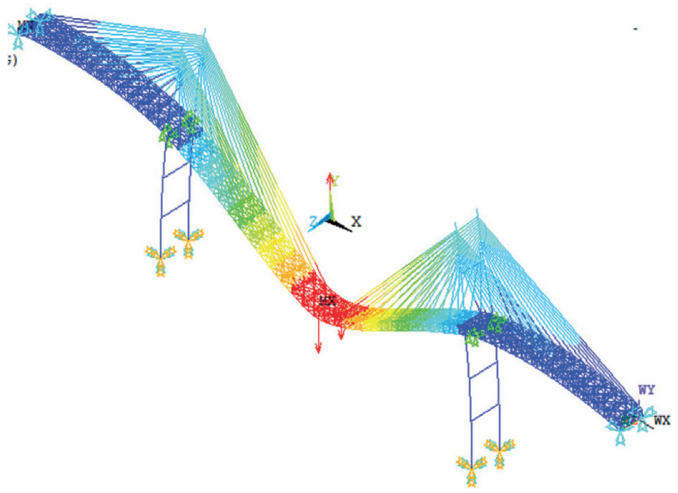

(d)

Figure 18: Collapse patterns of the bridge in different chord loss scenarios: (a) loss of chords A8-A9; (b) loss of chords A29-A30; (c) loss of chords A44-A45; (d) loss of chords A59-A58.

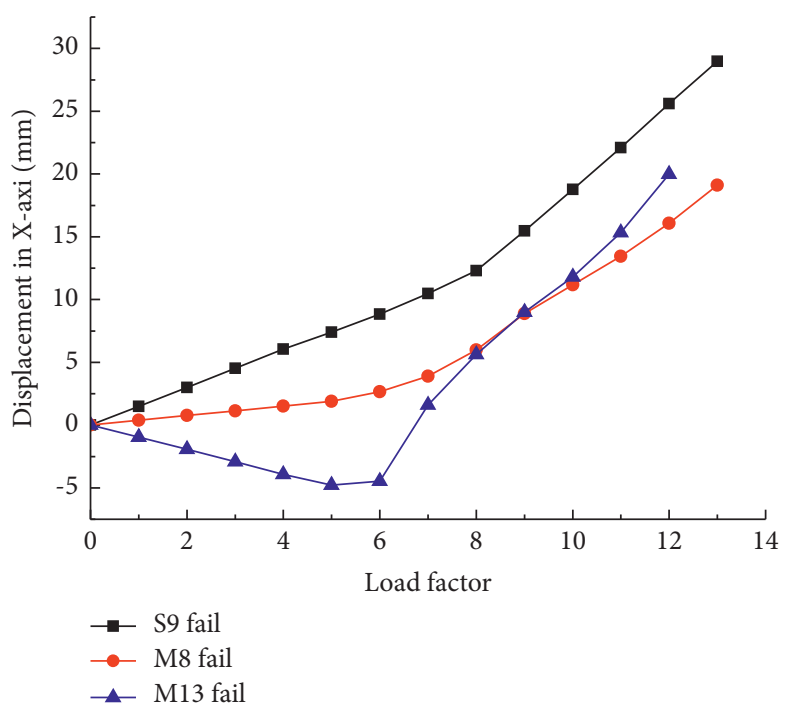

(a)

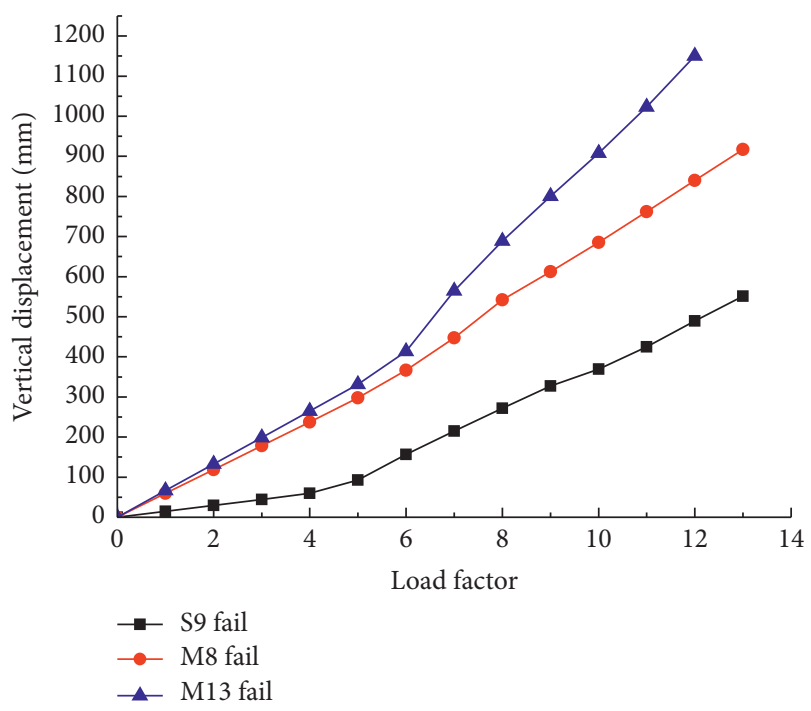

(b)

Figure 19: Displacement of the girder in the cable loss scenarios: (a) axial displacement-load response obtained from the finite element model; (b) vertical displacement-load response obtained from the finite element model.

values increase to $29 \mathrm{~mm}$ and $580 \mathrm{~mm}$, respectively, when the bridge is subjected to the most critical loading in the cable S9 loss scenario. These are the minimum values in the three cable loss scenarios. On the other hand, once a displacement of $4.7 \mathrm{~mm}$ is reached, the axial displacement value increases to $20 \mathrm{~mm}$ in the opposite direction when the bridge 


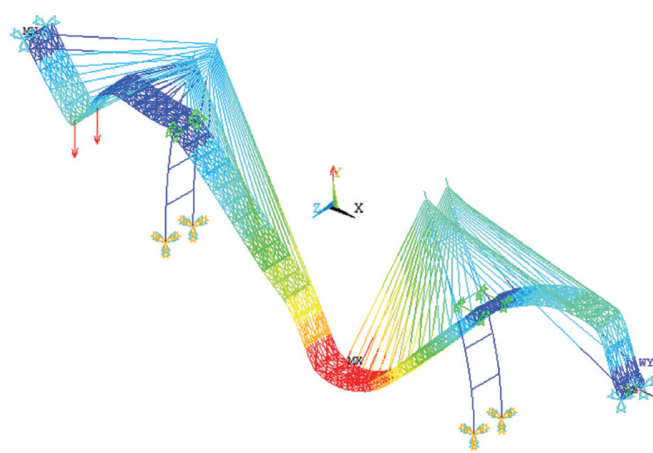

(a)

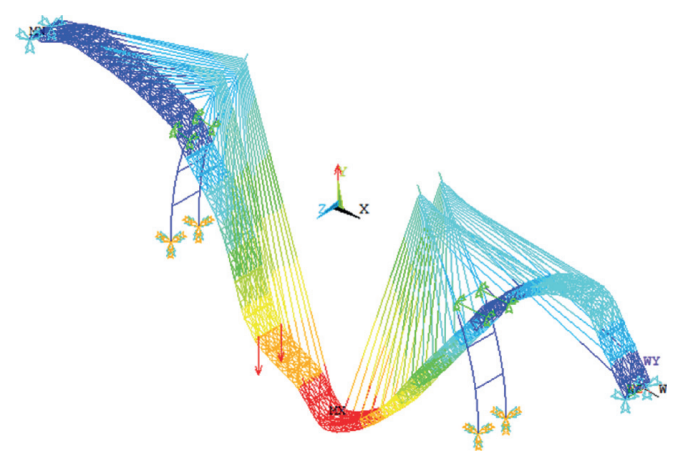

(b)

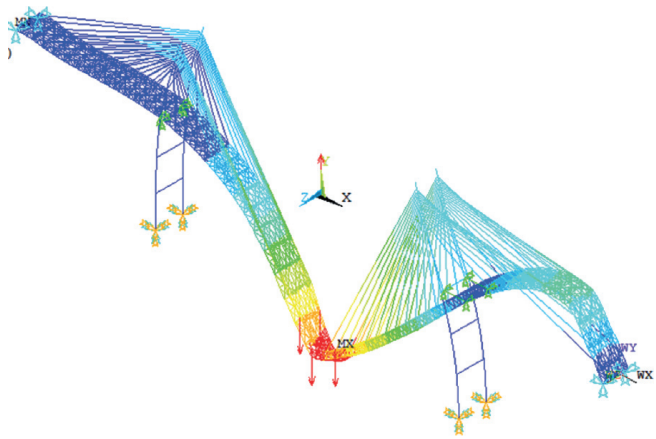

(c)

Figure 20: Collapse patterns of the bridge in different cable loss scenarios: (a) loss of cable S9; (b) loss of cable M8; (c) loss of cable M13.

TABLE 5: The collapse performance of the bridge in the cable loss scenarios.

\begin{tabular}{lcccc}
\hline Failed members & Node & Load factor & \multicolumn{2}{c}{$\begin{array}{c}\text { Maximum } \\
\text { displacement } \\
(\mathrm{mm})\end{array}$} \\
\hline S9 & & & Axial & Vertical \\
M8 & 18 & 12.9 & 29 & 580 \\
M13 & 90 & 13.1 & 21 & 960 \\
A8-A9 & 110 & 12.3 & 21 & 1150 \\
A29-A30 & 14 & 7.9 & 40 & 434 \\
A44-A45 & 54 & 12.0 & 5 & 31 \\
A59-A58' & 86 & 5.1 & -25 & 406 \\
\hline
\end{tabular}

collapses in the cable S13 loss scenario. The collapse patterns of the bridge for the different load scenarios are shown in Figure 20. The vertical displacement reaches $1150 \mathrm{~mm}$, which is the maximum value in the three cable loss scenarios (Table 5). The large deformation before the bridge collapse in the cable loss scenario shows that the parallel bearing system provides ample alternative paths for absorbing the load after the cable loss.

The chord loss does not result in a change in the cable forces under a dead load; however, the cable failure leads to a redistribution of the cable forces. A chord failure close to the pylon results in brittle damage of the entire bridge under a critical loading, whereas a cable loss leads to outstanding ductility of the remaining structure. In addition, the corrosion of the truss girder does not significantly influence the cable force and vertical displacement of the beam. Overall, the truss girder, a series bearing system, provides limited alternative load paths after the bridge is damaged by a chord loss. In contrast, the cables, a parallel bearing system, provide sufficient load paths for the bridges damaged by a cable loss.

\section{Conclusions}

An approach, taking into consideration a series-parallel load-bearing system and alternative load paths, is proposed to investigate collapse behavior of cable-stayed bridge with steel truss girders. This approach reveals structural load paths and collapse behavior. The loadbearing systems can also be used to evaluate and determine the damage to cable-stayed bridge and further improve their structural performance design. The conclusions are drawn as follows:

(1) A series-parallel load-bearing system of a cablestayed bridge is proposed to assess and determine alternative load paths in damaged bridges and attain structural ultimate bearing capacity.

(2) As a series bearing system, the loss of an individual chord in truss girders has negligible effects on the cable forces; thus, the truss girder can bear most of the load without required alternative loading paths. Similarly, corrosion in truss girder has highly slight effects on cable forces and vertical displacement in the main beam. In contrast, as a parallel bearing system, cables provides alternative paths to transfer the load when forces changed due to cable loss. 
(3) After individual chord failure, a brittle collapse of the damaged bridge occurs, with a maximum displacement of $40 \mathrm{~mm}$ along the longitudinal axis. The series bearing system of truss girders can transfer load in limited paths to other members in truss girder after failure of individual chords. Thus, additional bars should be recommended to add into truss girders to create more alternative load paths at mid-span and near pylon.

(4) Unlike the chord loss scenarios, the damagedbridges collapse after exhibiting significant deformation in cable loss scenarios due to the fact that the other cables absorbed loading; this effect is more pronounced when a long cable fails. As a parallel bearing system, cables provide various alternative paths to absorb loading if individual cables fail.For cable-stayed bridges with steel truss girders, bearing capacity in cables is required to be twice dead and live loads, which is less than 2.5 times recommended in specification.

\section{Data Availability}

The data used to support the findings of this study are available from the authors upon reasonable request.

\section{Disclosure}

Any opinions, findings, conclusions, or recommendations expressed in this paper are those of the authors and do not necessarily reflect the views of the institutions.

\section{Conflicts of Interest}

The authors declare no conflicts of interest with regard to the publication of this paper or the funding.

\section{Acknowledgments}

The authors wish to acknowledge the support of the Shaanxi Communication Science and Technology Project no. $20-45 \mathrm{~K}$ and the Fundamental Research Funds for the Central Universities, CHD no. 300102210116.

\section{References}

[1] 2017, https://www.mprnews.org/story/2017/08/01/lookingback-photos-of-the-bridge-collapse.

[2] T. R. Witcher, "From disaster to prevention: the Silver Bridge," Civil Engineering, vol. 87, no. 12, pp. 44-47, 2017.

[3] M. Ghosn, J. Yang, D. Beal, and B. Sivakumar, "Bridge system safety and redundancy," No. Project, vol. 12-86, 2014.

[4] P. C. Pandey and S. V. Barai, "Structural sensitivity as a measure of redundancy," Journal of Structural Engineering, vol. 123, no. 3, pp. 360-364, 1998.

[5] A. M. Nafday, "System safety performance metrics for skeletal structures," Journal of Structural Engineering, vol. 134, no. 3, pp. 499-504, 2018.

[6] C. T. Hunley and I. E. Harik, "Structural redundancy evaluation of steel tub girder bridges," Journal of Bridge Engineering, vol. 17, no. 3, pp. 481-489, 2011.
[7] M. Ghosn and F. Moses, "Redundancy in highway bridge superstructures," Transportation Research Board, vol. 406, 1998.

[8] J. Scheller and U. Starossek, "A new energy-efficient device for active control of bridge vibrations," International Association for Bridge and Structural Engineering, vol. 17, no. 12, pp. 310-311, 2008.

[9] C. M. Mozos and A. C. Aparicio, "Parametric study on the dynamic response of cable stayed bridges to the sudden failure of a stay, part II: bending moment acting on the pylons and stress on the stays," Engineering Structures, vol. 32, no. 10, pp. 3301-3312, 2010.

[10] C. M. Mozos and A. C. Aparicio, "Parametric study on the dynamic response of cable stayed bridges to the sudden failure of a stay, part II: bending moment acting on the pylons and stress on the stays," Engineering Structures, vol. 32, 2010.

[11] F. Greco, P. Lonetti, and A. Pascuzzo, "Dynamic analysis of cable-stayed bridges affected by accidental failure mechanisms under moving loads," Mathematical Problems in Engineering, vol. 20, pp. 130-137, Article ID 302706, 2013.

[12] P. Lonetti and A. Pascuzzo, "Vulnerability and failure analysis of hybrid cable-stayed suspension bridges subjected to damage mechanisms," Engineering Failure Analysis, vol. 45, pp. 470-495, 2014.

[13] D. Yan and C. C. Chang, "Vulnerability assessment of singlepylon cable-stayed bridges using plastic limit analysis," Engineering Structures, vol. 32, no. 8, pp. 2049-2056, 2010.

[14] C. T. Hunley and I. E. Harik, "Structural redundancy evaluation of steel tub girder bridges," Journal of Bridge Engineering, vol. 17, no. 3, pp. 481-489, 2011.

[15] W. H. Wu, S. W. Wang, C. C. Chen, and G. L. Lai, "Assessment of environmental and nondestructive earthquake effects on modal parameters of an office building based on long-term vibration measurements," Smart Materials and Structures, vol. 26, no. 5, Article ID 055034, 2017.

[16] T. N. Kudsi and C. C. Fu, "Redundancy analysis of existing truss bridges: a system reliability-based approach," in Proceedings of the First International Conference Bridge Maintenance, Safety and Management, 2002.

[17] M. Ghosn, F. Moses, and D. M. Frangopol, "Redundancy and robustness of highway bridge superstructures and substructures," Structure and Infrastructure Engineering, vol. 6, no. 12, pp. 257-278, 2010.

[18] J. Yang, "Structural redundancy and system reliability of highway bridges," Doctoral dissertation, The City College of, New York, 2015.

[19] M. Ghosn, D. M. Frangopol, T. P. McAllister et al., "Reliability-based performance indicators for structural members," Journal of Structural Engineering, vol. 142, no. 9, Article ID F4016002, 2016.

[20] M. Ghosn, L. Duenas-Osorio, D. M. Frangopol et al., "Performance indicators for structural systems and infrastructure networks," Journal of Structural Engineering, vol. 142, no. 9, Article ID F4016003, 2016.

[21] J. W. Baker, M. Schubert, and M. H. Faber, "On the assessment of robustness," Structural Safety, vol. 30, no. 3, pp. 253-267, 2008.

[22] V. Janssens, D. W. O'Dwyer, and M. K. Chryssanthopoulos, "Assessing the consequences of building failures," Structural Engineering International, vol. 22, no. 1, pp. 99-104, 2012.

[23] B. M. Imam and M. K. Chryssanthopoulos, "Causes and consequences of metallic bridge failures," Structural Engineering International, vol. 22, no. 1, pp. 93-98, 2012. 
[24] B. Zhu and D. M. Frangopol, "Risk-based approach for optimum maintenance of bridges under traffic and earthquake loads," Journal of Structural Engineering, vol. 139, no. 3, pp. 422-434, 2012.

[25] B. Zhu and D. M. Frangopol, "Reliability assessment of ship structures using Bayesian updating," Engineering Structures, vol. 56, pp. 1836-1847, 2013.

[26] C.-C. Chen, W.-H. Wu, C.-Y. Liu, and G. Lai, "Diagnosis of instant and long-term damages in cable-stayed bridges based on the variation of cable forces," Structure and Infrastructure Engineering, vol. 14, no. 5, pp. 565-579, 2018.

[27] C. J. Song, G. Zhang, X. Y. Li, and V. K. R. Kodur, "Experimental and numerical study on failure mechanism of steel-concrete composite bridge girders under fuel fire exposure," Engineering Structure, vol. 247, Article ID 113230, 2021.

[28] X. Y. Li, G. Zhang, V. K. R. Kodur, S. H. He, and Q. Huang, "Designing method for fire safety of steel box bridge girders," Steel and Composite Structures, vol. 38, no. 6, pp. 657-670, 2021.

[29] G. Zhang, V. K. R. Kodur, W. F. Yao, and Q. Huang, "Behavior of composite box bridge girders under localized fire exposure," Structural Engineering \& Mechanics, vol. 69, no. 2, pp. 193-204, 2019.

[30] G. Zhang, V. K. R. Kodur, J. C. Song, S. H. He, and Q. Huang, "A numerical method for evaluating fire resistance of composite box bridge girders," Journal of Constructional Steel Research, vol. 165, Article ID 105823, 2020.

[31] X. M. Wang, "ANSYS Structural analysis element and application," (In Chinese), China Communication Publishing \& Media Management Co., Ltd., 2011. 